\title{
Moving Video Camera Base on Expression Dancer Move and Kinesphere
}

\author{
NRA Candra DA ${ }^{1}$, Nur Rokhim ${ }^{2}$, Ranang AS $^{3}$, and Muji Soewasta ${ }^{4}$ \\ ${ }^{1}$ Television and Film Study Program, Faculty Fine Art dan Design, Indonesia Institute of the Arts in Surakarta \\ ${ }^{2}$ Dance Study Program, Faculty Performing Art, Indonesia Institute of the Arts in Surakarta \\ ${ }^{3}$ Television and Film Study Program, Faculty Fine Art dan Design, Indonesia Institute of the Arts in Surakarta \\ ${ }^{4}$ Photography Study Program, Faculty Fine Art dan Design, Indonesia Institute of the Arts in Surakarta
}

E-mail: candra@isi-ska.ac.id; 2) ranang.as@ gmail.com; 3) rocimduelike@yahoo.com; 4) muji@isi-ska.ac.id

\begin{abstract}
Video has become the medium of choice for documenting work of dancing performed in limited space and time. Nevertheless, there is something that most people still miss in creating the video work of a dance, that is the reduced dance expression that is expressed by the dancers. Visual dance in a video camera is just as a spectacular "spectator" that is translated by the eyes of a videographer. The video camera has not been positioned as a dancer and the purpose of the dance movement itself. The videographer has not looked at the dancer as a reference for the visualization of his video work. Though the dancer also has a conception and expression embodied in the movement of her dance. Through this research, the researcher is interested to reveal the expression of dance movement through the medium of art video, by trying to bring together the dance / choreographer's conception of motion and visual conception of videographer. This artistic research uses an experimental research approach. The research procedure is carried out in two stages: Analysis and Development / Pro duction. The analysis involves the identification and studying of the object of the research (dance movement) and the formulation of motion concept based on the motion of dance. The result of research show that the placement of a video camera (blocking video camera) should really be considered and used when in some parts of the dance movements, especially fast and quick movements, moving from one point to another. The selection of certain types of shots like Close Up, Medium Close Up and others are used when there are dance movements, especially those that use flexibility of hand motion, feet, and even the expression of the dancer's face.
\end{abstract}

Keywords Dance moves, cinematography, dance videos, and kinesphere

\section{Introduction}

Developments in the field of knowledge and technology, especially related to the art of media is growing rapidly. The needs of audio visual technology has penetrated all aspects of human life which is no exception to the art of production with video cameras. Just as audio visual has now become the medium of choice for the effort of recording works of art such as dance work staged in limited space and time. However, there is something that most people still miss in creating a video work of a dance, which reduces the expression of dance moves revealed by the dancers. The camera is only placed in the "glasses" / point of view of the audience by the videographer. The camera has not been positioned as the dancer and the dance movement itself.

During this time most video works about dance is limited to video documentation only. The expression of the videographer and the dancer / choreographer has not been included in the video work. In production, videographers generally work alone without involving the dancer as a ref- erence, and the dancers are only placed as mere objects by the videographer. Videographers have not yet to view dancers as a reference for visualization of their video work. Though the dancers also have conception and expression embodied in the movement of their dance. So in the dance documentary video so far seems "loose" between the videographer and dancer / choreographer, there's not yet a unity within the framework of shared expression.

The dance videos in the West are known for several terms, in his book, Dodds mentions the existing terms include 'screen choreography' (Jordan, 1992), 'dance video creation' (Chaurand, 1993), 'camera choreography' (Brooks, 1993), 'dance for the camera 'and' video dance '(Maletic, 1987; Rosiny, 1994; Pritchard, 1995). Furthermore, Dodds, says that all these terms of stress are a relationship between the medium of dance and a facet of the film or television media [1]. In Indonesia, dance videos have not been a work of art that has an adequate existence compared to other audio visual artworks, such as short films, documentary films and video art. 
Dance videos are choreographic creations revealed only through the medium of film / video [2]. Dance videos are created, according to Rodrigo Alonso, when choreographers and directors are experienced in translating dance from stage to screen [1]. Dance Film is also understood as an interpretation of the work of dance mainly created for live performances. Definition of Videodance is a motion-based and orchored-based movement to show it on a single screen both television, monitor or projector - and it is a stand-alone work, not from a live performance part. As it was in the UK since 2003, the online dance video community [3]. The existence of Dance Video in Indonesia has not grown well, unlike in abroad. Currently Video Dance is in the middle of a popularity boom, pushed by the ever-increasing availability and flexibility of digital video technology.

The problem of concern in this experimental study is the need for a dance video work which is not as a video documentation of dance performances but as a video that is in harmony with the dancers' expression of motion. Specifically these needs can be explained as an expression of dance moves revealed by dancers can be implemented on a video work of dance through the characteristics of video camera movement. The dance video results of this study is not a documentary video but the result of an experiment and exploration of camera motion that is aligned with the dance moves and dance expressions revealed by the dancers and seeks to bring the conception of the dancer's movements with the visual conception of a videographer. This is a differentiator of this research from the existing video documentation of dance, which is only a documentary work.

\section{Literature Review}

\section{Video Dance}

The understanding of Dance Videos is identical to Dance Film, Dance Film is also understood as an interpretation of the dance masterpiece primarily created for live performances (live). Definition Videodance is a motion-based and orchored-based movement to show it on a single screen both with a television monitor and with a projector and it is a stand-alone work not from a live performance. As it was in the UK since in 2003, an online community of 'Video Dance' [3]. It has presented information and works related to contemporary video and dance. In addition, online media is also open the opportunity for contributions in the form of criticism, review, or articles about dance video

The existence of Dance Video in Indonesia has not grown well, unlike in abroad. Currently Dance Video is in the middle popularity of fiction films and short films, driven by the increasing availability and flexibility of digital video technology. Artists are enabled to create works by doing only the creative spirit. In the Overseas there has been the Dance Films Association (Dance Films Association) in New York, even regularly organizing Dance On Camera Festival. In addition there is also a Council of Ontario Drama and Dance Educators (CODDE) which provides training on Exploring Dance Film. He focuses on the genre of dance movies. Par- ticipants will use various literature sources as a stimulus and use the knowledge of their dance elements as a basis for creating a choreography for the film.

Now most people are creating such a Video Dance works using digital video technology, in part or all of the production stages. However, the term Video Dance does not exclude works that have been worked on or even edited using the movie format. This is somewhat relevant for all the terms used to describe relatively new art forms that avant-garde dance approaches make innovations in video art, film making, and televisual practice. Another term com- monly used to describe this type of work is, dance film (dance film). dance on screen (dance on screen), cine dance, and now more commonly screendance.

Video Dance is a contemporary term for the dance genre made for cameras. In video dance, expressive movements are a key element in the work rather than the elements of dialogue (as in conventional narrative films) or musical elements (as in music videos). Other names for this form are screendance, dance film, cinedance, and dance for camera.

Since movement is the basic element in all forms of timebased visual media, Video Dance is distinguished from other film genres with an emphasis on skills and motion composition in the work. Often this movement is recognized as a dance in which people move in a stylish way, but in some videodances, animations and experimental movements can be objects or other objects such as animal movement and inanimate objects.

A related genre that is often confusing with Video Dance is a dance documentary. This is a dance documentation as practiced in real life such as a live or journalistic profile of a dance institution, figure, or dance community. Video Dance is not a documentation of dance that can be performed in real time in real shows. It exists only as a fictional or fictionalized dance for the screen.

A related genre that is often confusing with Video Dance is a dance documentary. This is a dance documentation as practiced in real life such as a live or journalistic profile of a dance institution, figure, or dance community. Video Dance is not a documentation of dance that can be performed in real time in real shows. It exists only as a fictional or fictionalized dance for the screen.

\subsection{Setting of Video Camera in the Video Dance}

When the expression of the work of dance developed for the purpose of audio visual art work as well as the dance video then will certainly expand on the understanding of a videographer in an effort to portray himself and to make a concept of cameraman language is more varied in terms of cinematography techniques. In fact, the dance video is able to bring together two different art forms namely video art and dance art. Certainly, it combines many creative elements in it, such as the design of lights and sounds provide great potential as a creative medium. It also has meaning in every case, the production process of the dance video will bring various artists and experts who come together in achieving one goal [4]. 
The use of a camera for dance has emerged for various reasons. The camera frames the world of dance, so it can produce mood and create an atmosphere because it can convey emotions, stories, present perspectives and parts of the action. Through the use of shooting and different shooting angles, the camera is able to take the viewer's point of view to put a viewpoint that they do not usually get. The lens can enter the dancers kinesphere which is a personal area around dancers moving with it as a dancer so focus on motion detail and allow an intimacy or closeness that can not be reached within the context of live performances.

According to Dayna Chun, directors also become creative in positioning cameras through different angles or putting cameras on revolving platforms ("Dance") [5]. The director has an important role managing the crew and directing the shooting. How the camera moves in relation to the dancer is also an important aspect in video dancing. As a camera stylist the necessity of whether by handheld, or by using jimmy jib by moving through space. That is what can change the perception of dance audiences when combining their three-dimensional, creating changes and visual experiences directly [4].

Showing the dance in video format is able to explore the angle of the audience from a point of view that they do not usually get. The audience is not only positioned as an audience with distance to the dancers, but also as a 'part' of the dancer and every their moves. How a series of images (shots) can describe a motion through the position of the camera, the movement of the camera and some types of shots that have a certain character in conveying the message. The basic principle of camera / audiovisual should be a concern as well, because beside the understanding of dance as a whole in one body of the show also become two important things that will be collaborated. According to Dayna Chun, the relationship between the dancer and the camera was one of their top priorities in creating exciting musicals [5]. In addition the camera position and movement of the camera also pay attention to Kinesphere: the area where the body moves inside and how the mover takes notice for it.

\section{Method}

This research uses experimental research approach. The research procedure is carried out in two stages, Analysis and Development. The analysis includes identification activities and reviewing the object of research (dance movements) and the development related to the concept of video camera motion based on the motion of the dance (kinesphere). Selection of research object with Purposive Sample technique, done selectively and limited to only the dance performed by a dancer who already has a strong foundation in bringing a dance masterpiece. In this artistic research assisted by a young dancer named Puji Sri Lestari who is a seventh semester student from Dance Study Program, Faculty of Performing Arts, ISI Surakarta.
The primary data in this study is a dance that has been existed then observed and was breakdowned based on synopsis, pattern of motion and pattern of the floor. In digging the data will be used Observation method and Brainstorming method (brainstorming). Observations are directed at the acquisition of data in the form of identification on dance movement and kinesphere which become the essence of the dance video experiment. From the analysis activities that resulted an integration of conception (dancers and videographers) above, followed by experimental / production activities including pre production, production, and post production. Pre-production includes scriptwriting, scenarios, and storyboards. Production includes video shooting and dance performances itself. While post production includes audio-video editing, with ouput in the form of video cassette and DVD.

\section{Discussion}

Retno Pamudya dance was chosen as an object in this artistic research because this dance is one of the original sourced dance from the Surakarta and has long been present in the society. This dance is a creation of Raden Tumenggung Koesumokesowo. This dance tells about the courage of a Srikandi who fought against Bisma. In this dance is performed by a princess named Srikandi who is very skilled in playing weapons in the form of Cundrik and arrows skillfully. But at least she still did not leave from her figure as a woman, Srikandi figure of course still show us about the softness, smoothness, and patience.

Retno Pamudya dance is divided into four sections: Maju Beksan, Beksan, and Mundur Beksan. In the Maju Beksan section (movement in the beginning), describes the form of 'Semedi' in order to carry out the task of fighting against Bisma to gain victory and having strong spirit in the fight against her own uncle. In the part of beksan (middle or main movement), this dance depicts Srikandi figure as a woman character who has softness, smoothness, and patience as her nature. This section also shows scenes in a battle featuring fast and quick movements and skill in using 'Cundrik' weapons and arrows against Bisma, but the figure of Bisma is not shown. At the end is the Mundur Beksan (final movement or closing), meaning that after ending any activity do not forget to always pray to the Almighty God.

From the range of Retno Pamudya dance movements, mainly the three basic parts in the dance movement, can be generated a series of images or visualizations that are the result of exploration with the types and motion of shots of a video camera based on the expression of the dancers and kinesphere in accordance with the dance characters performed.

From this research can be formulated two main subjects related to the visualisation of the dance movement, especially the type of classical Javanese dance - Retno Pamudyo by using a video camera that records dance movements. First, there are many dynamic patterns or motions that require the 
proper video camera blocking so that the dynamics of dance movements can still be captured properly by the video camera. Second, that in the characteristic dance Retno Pamudya show there are some typical movements such as special movements of hands, feet, and the expression of the dancer's face.

\section{Dynamic Motion Dance through Camera Blocking}

Although Retno Pamudya dance is a classical Javanese dance, it contains dynamic movements. To be able to capture the dynamics that wrap the softness, demanding the right camera placement. Below are some video camera blocking that is adapted to the division of the typical movement in Retno Pamudya dance.

$a$. The rotating pattern on the movement of maju beksan

One form of early movement (Maju Beksan) in Retno Pamudya dance is a circular motion and back to the center. Description of that movement is Debeg Gejug left holding Gendhewa (arrow), right hand hold sampur (shawl). The typical dance movement of Retno Pamudya at the beginning should be fully captured by the video camera along with several camera shoot types that is Full Shot and Estabilish Shot.
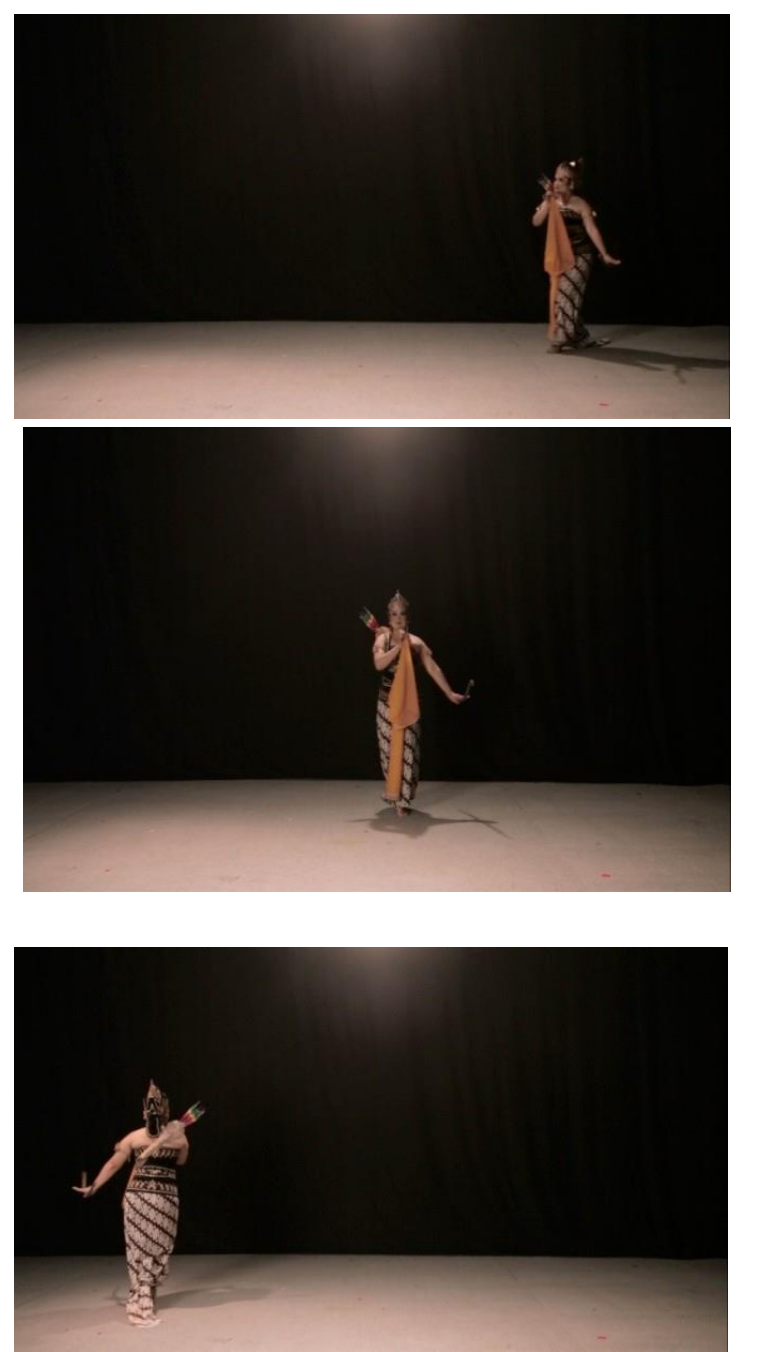

Figure 1. Movement of Debeg Gejug (above), and left hand holding the Gendhewo (bottom)

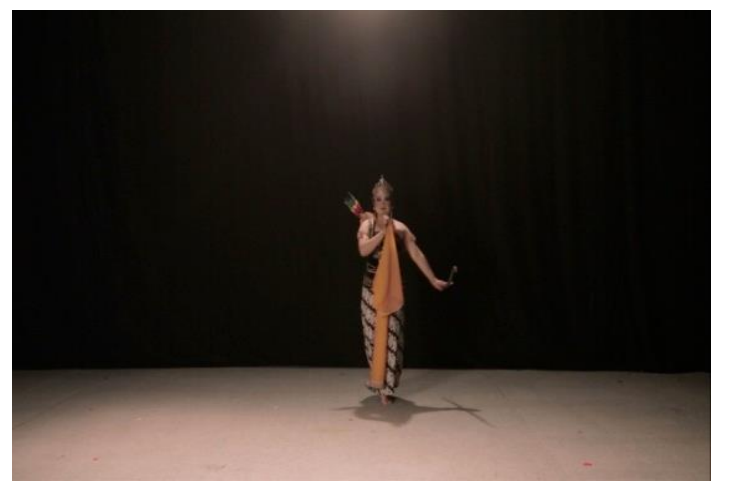

Figure 2. Left Debeg-Gejug movement,

the left hand holds the Gendhewo (above), and the right hand holds the Sampur (bottom)

b. The pattern of diagonal sideways movement in the main movement (Beksan)

Below is the form of movement in Retno Pamudya dance which is included in the middle or main movement (Beksan). The pattern of movement is to start from going to the center dancing around then stopping at one point at the center and then doing sideways move right and left and diagonally backwards. Description of the movement is Mundur Enjer with Samparan (scarf) stepped, then motion Debeg Gejug left, take the right Sampur (scarf) then forward left foot and movement Jengkeng. With such a movement, then the placement of a video camera should also be able to record the full range of movement of the Beksan in Full Shot, Establish Shot, and in still position.

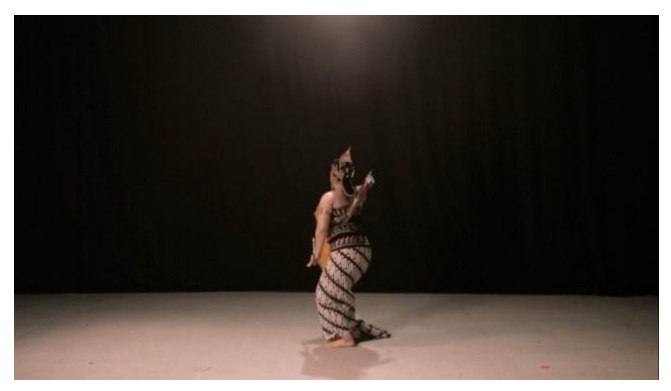

Figure 3. The motion of mundur enjer with surpassed samparan (1)

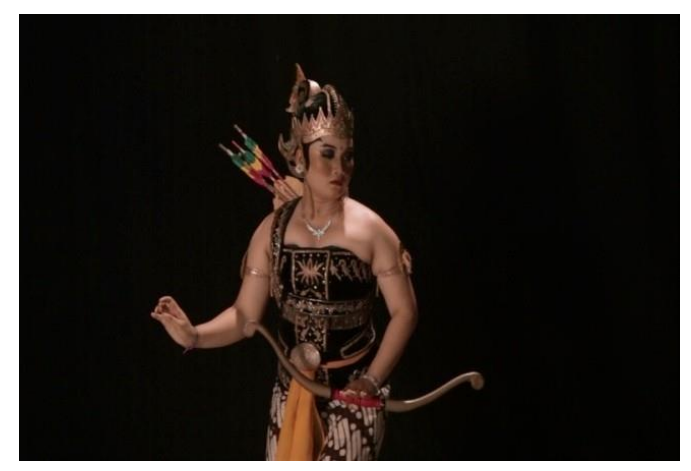

Figure 4. The motion of mundur enjer with surpassed samparan (2) 


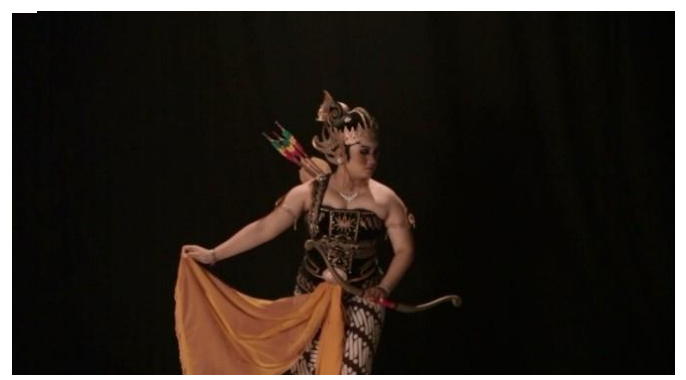

Figure 5. The motion of mundur enjer with the surpassed samparan (3)

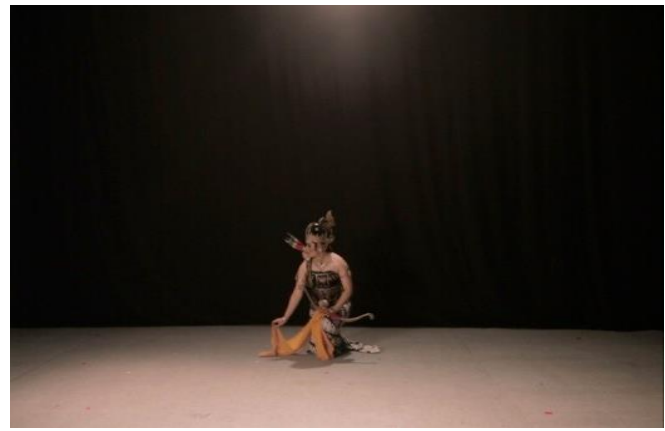

Figure 6. Movement of debeg gejug left (above), take the right sampur forward left foot and then jengkeng movement (bottom).

c. The motion pattern is centered in the final movement of mundur beksan

The image below is a series of movements in the Retno Pamudya dance which is included in the final or closing movement (mundur beksan / backward beksan). The description as in the following movements, drag the right front hand to the front of the puser and then the ukel wutuh. Video camera placement can fully recording with Full Shot and Long Shot, then follow the movements of the dancers. After that the dancers do srisig moves to the front right corner, gejuk right leg, left handed menthang gendhewa, right hand nyekithing trap cethik, left debek gejuk, left hand pulled in front of ear, right hand menthang, mancat to srisig. Placement and shooting with a video camera is still relatively the same as before.

Then the last movem ent is srisig to the front right corner, right leg gejuk, left handed menthang gendhewa, right hand nyekithing trap cethik, left debek gejuk, left hand pulled in front of ear, right hand menthang, mancat to srisig. The movement became the end of Retno Pamudya dance performance.

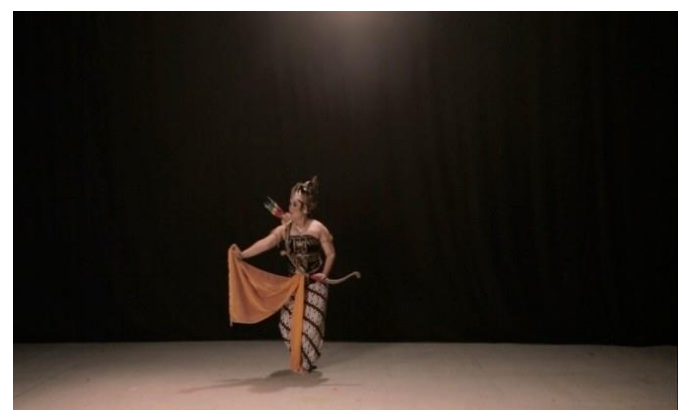

Figure 7. Movement of maju beksan: (left) Right foot gejuk, left hand menthang-gendhewa, (right) right hand nyekithing trap cethik and dhe-bek-gejuk left.

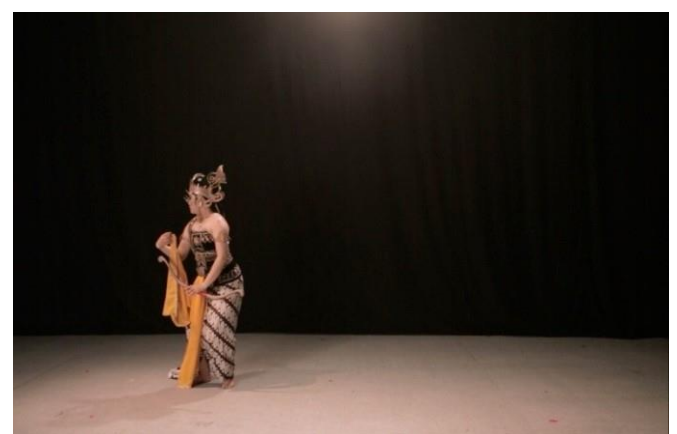

Figure 8. Movement of maju beksan: (left) Right foot gejuk, left hand menthang-gendhewa, (right) right hand nyekithing trap cethik and dhebek-gejuk left. (2)

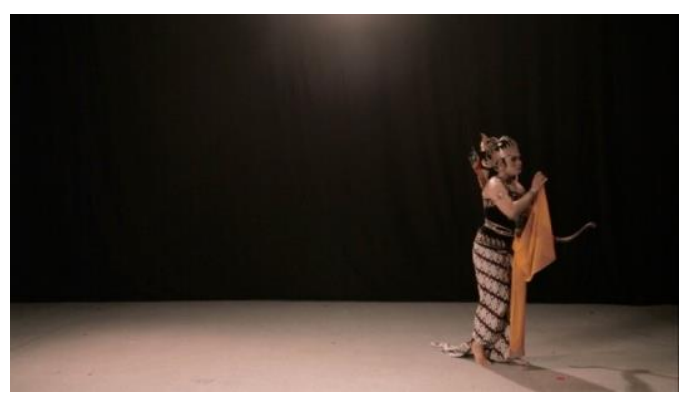

Figure 9. Movement of maju beksan: srisig movement toward the front right corner

\section{Dance Motion Expression through Close Up}

Dance Retno Pamudya has some specific movements and specific that become its characteristic, namely the motion of the hands, feet, and expression of the dancer's face. The type of shot and motion of the video camera used in the arrangement of videography should be able to clearly show the motion expressions of the hands, feet and faces of the dancer. Here is an example of some Retno Pamudya dance movements that show the specificity of the motion.

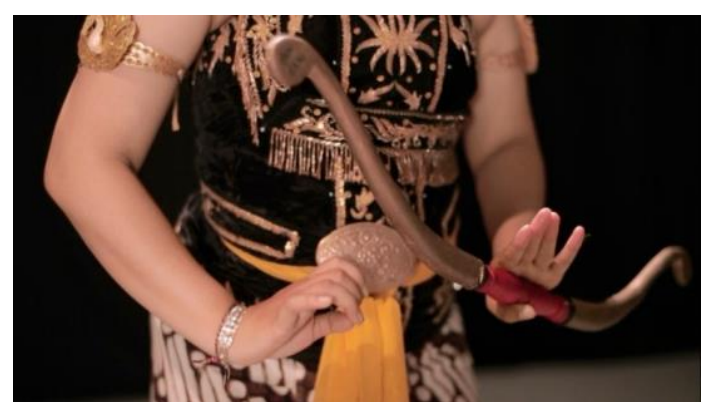

Figure 10. Hand movement of kebyok sampur leyeh with Camera: Close $\mathrm{Up}$

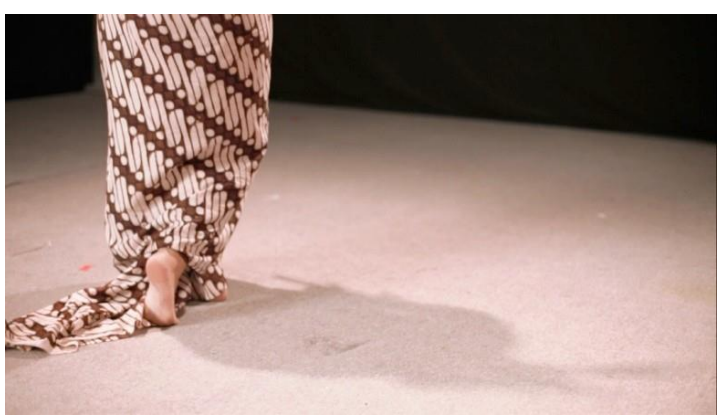

Figure 11. Foot movement, gejug right foot with Camera: Medium Close Up 


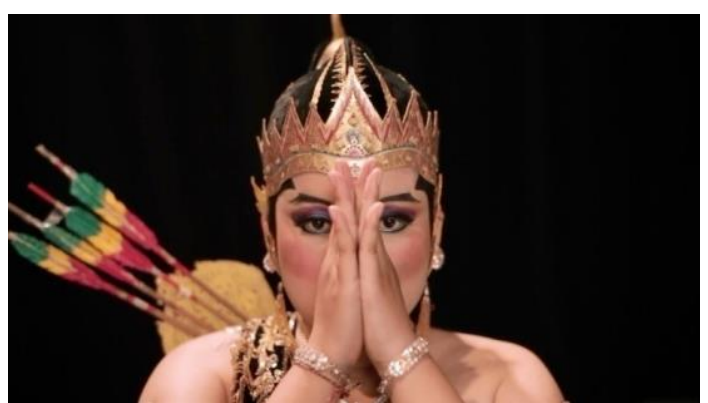

Figure 12. The dancer's facial expression with kebyok sampur in type shot: Close Up

The dance works that have been known with all forms, origin, types and people names owned respectively, it turns out with the help of recording devices such as video cameras can be enjoyed by anyone who watches even by the people that is poor about the performance of artwork. Dance performances which usually seen only at a glance and sometimes we override the existing detail on the dance such as the movements on certain parts of the dancer as the motion of the hands, feet, even the face expression.

Through experimental research with an artistic approach that combines the field of cinematography and the art of dance, a comprehensive understanding of dance performances is obtained. In recording dance performances using video cameras, an artistic and technical approach of shooting or cinematographic aspects which is appropriate, and based on the manuscripts and motions of a work of the dance itself. Classical Javanese dance entitled Retno Pamudya that has been studied their aspects, ranging from story content, de- scription of motion, to the pattern of movement. From the study, then using the basic language of images or sinemo- tografi visually combined with the division of movement in Retno Pamudya dance. From the detail range of motion of Retno Pamudya dance is obtained a series of images or vis- ualization, as a result of exploration with the types and mo- tion of the shot of a video camera based on the expression of dancers and kinesphere when the dance performed.

\section{Conclusion}

In the end, it can be concluded that in classical Javanese dance such as dance Retno Pamudya need to note the uniqueness of movement in each section essentially the maju beksan, beksan and mundur beksan. The placement of a video camera (blocking video camera) should really be considered and used when in some parts of the dance movements, especially fast and quick movements, moving from one point to another.

The selection of certain types of shots like Close Up, Medium Close Up and others are used when there are dance movements, especially those that use flexibility of hand motion, feet, and even the expression of the dancer's face. Thus the result of video exploration based on the dancers' expression is very different when compared with the only dance documentation video which is just a reporting.

\section{REFERENCES}

[1] S. Dodds, Dance on Screen : Genres and Media from Hollywood Experimental Art. 2001.

[2] "Wikipedia," Wikipedia. .

[3] "Videodance.".

[4] K. McPherson, Making Vido Dance : A Step-by-Step Guide to Cr ing Dance for the Screen. Routledge, 2006.

[5] D. A. Peransi, Film/Media/Seni. Jakarta: Penerbit FFTV-IKJ Pr 2005.

[6] D. Chun, "Essence of Dance and a Camera," Mānoa Horiz., vol. 2, 2017. 